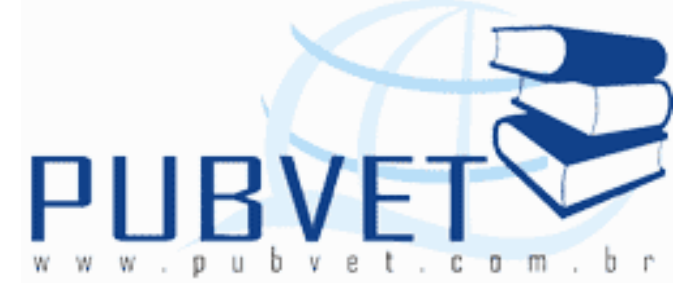

PUBVET, Publicações em Medicina Veterinária e Zootecnia.

\title{
Produção e composição química de Panicum maximum cv. Mombaça sob diferentes níveis de potássio
}

Newton de Lucena Costa ${ }^{1}$; Valdinei Tadeu Paulino ${ }^{2}$; Maria Socorro de Souza Carneiro ${ }^{3}$; João Avelar Magalhães ${ }^{4}$; Terezinha Ferreira Xavier ${ }^{5}$; Lucia Elenícia da Silva Nascimento ${ }^{6}$; Francisca Mirlanda Vasconcelos Furtado ${ }^{7}$

1 Eng. Agr., M.Sc., Pesquisador da Embrapa Roraima. Doutorando em Agronomia/Produção Vegetal, UFPR, Curitiba, PR.

2 Eng. Agr., Ph.D., Instituto de Zootecnia, Nova Odessa, SP.

3 Eng. Agr., D.Sc., Professora do Programa Pós-Graduação em Zootecnia da UFC, Fortaleza, CE.

${ }^{4}$ Med. Vet., D.Sc., Embrapa Meio Norte, Parnaíba, PI.

${ }^{5}$ Eng. Agr., M.Sc., Profa. do Instituto Federal de Roraima, Amajari, Roraima. Doutoranda em Agronomia/Ciência do Solo, UNESP Jaboticabal, SP.

${ }^{6}$ Estudante de Pós-Graduação em Gestão Ambiental e Ecoturismo, Faculdade Montenegro. Parnaíba, Piauí.

${ }^{7}$ Zootecnista, M.Sc., Doutoranda em Zootecnia, UFC, Fortaleza, CE.

\section{Resumo}

O efeito de níveis de potássio $\left(0,15,30,45\right.$ e $60 \mathrm{mg}$ de $\left.\mathrm{K} / \mathrm{dm}^{3}\right)$ sobre o rendimento de matéria seca (MS) e composição química de Panicum maximum cv. Mombaça foi avaliado sob condições de casa-de-vegetação. Os rendimentos de MS e os teores de potássio foram incrementados $(P<0,05)$ pela adubação 
potássica, ocorrendo o inverso quanto aos teores de proteína bruta e fósforo, enquanto que os teores de cálcio e magnésio não foram afetados pelos níveis de potássio. Os maiores rendimentos de MS, teores de potássio e eficiência de utilização do potássio foram obtidos com a aplicação de 51,5; 55,4 e 47,5 mg de $\mathrm{K} / \mathrm{dm}^{3}$, respectivamente. O nível crítico interno de potássio relacionado com $90 \%$ do rendimento máximo de MS em 1,75\%.

Palavras-chave: cálcio, fósforo, magnésio, matéria seca, proteína bruta

\title{
Production and chemical composition of Panicum maximum cv. Mombaça under different levels of potassium
}

\begin{abstract}
The effect of potassium levels $\left(0,15,30,45\right.$ and $60 \mathrm{mg}$ of $\left.\mathrm{K} / \mathrm{dm}^{3}\right)$ on dry matter (DM) yield and chemical composition of Panicum maximum cv. Mombaça, was evaluated under greenhouse with natural conditions of light and temperature. Potassium fertilization significantly $(P<0.05)$ increased $D M$ yields and potassium contents, however, crude protein and phosphorus contents were depressed, while calcium and magnesium contents were not significantly affected by potassium fertilization. Maximum DM yield, potassium contents and potassium efficiency utilization were obtained with the application of 51.5; 55.4 and $47.5 \mathrm{mg}$ of $\mathrm{K} / \mathrm{dm}^{3}$, respectively. Internal potassium requirement for $90 \%$ maximum DM yield was estimated at $1.75 \%$.
\end{abstract}

Keywords: calcium, crude protein, dry matter, magnesium, phosphorus

\section{Introdução}

De origem africana e de hábito de crescimento cespitoso, o capimMombaça foi introduzido na América em 1967, e, após um longo trabalho de seleção, foi liberado em 1993 no Brasil, pela Embrapa Gado de Corte. É uma cultivar da espécie Panicum maximum, de grande produtividade, elevada porcentagem de folhas, destacando-se também por apresentar menor estacionalidade do que outras gramíneas da mesma espécie (JANK et al., 
1994; SANTOS, 1997; MULLER et al., 2002; MOCHEL FILHO, 2009; REYNOSO et al., 2009). Na Amazônia Ocidental, a gramínea se destacou pela elevada produtividade de forragem e bom valor nutritivo, além de sua moderada resistência às cigarrinhas-das-pastagens (Deois incompleta) (COSTA 1996; COSTA et al., 2007).

De outro lado, os solos de Rondônia apresentam, originalmente, teores médios ou altos de potássio trocável, sendo rara a resposta de gramíneas forrageiras à adubação potássica. No entanto, face ao uso de práticas de manejo inadequadas (elevadas cargas animais, sistema de pastejo sob lotação contínua e ausência de fertilizações de estabelecimento e/ou manutenção), as quais afetam consideravelmente a eficiência dos processos de reciclagem de nutrientes, nos últimos anos, o aparecimento de deficiências de potássio nas pastagens cultivadas tem sido bastante frequente (COSTA et al., 2007).

Ensaios exploratórios de fertilidade do solo realizados na região amazônica demonstraram que o potássio, depois do fósforo, foi o nutriente mais limitante ao crescimento de Paspalum atratum cv. Pojuca e Panicum maximum cvs. Mombaça e Centenário, reduzindo significativamente seus rendimentos de forragem, perfilhamento, teores de nitrogênio e potássio (COSTA, 1996; COSTA et al., 2004a,b). Em pastagens de Brachiaria brizantha cv. Marandu, estabelecidas em um Latossolo Amarelo, textura argilosa, com baixa disponibilidade de potássio $(51 \mathrm{mg} / \mathrm{kg})$, COSTA et al. (2004b), com a aplicação de $40 \mathrm{~kg}$ de $\mathrm{K}_{2} \mathrm{O} / \mathrm{ha}$, obtiveram incrementos de 65; 38 e 81\%, respectivamente para os rendimentos de forragem e quantidades acumuladas de potássio e nitrogênio. GODOY et al. (2007) destacaram que o potássio é o segundo nutriente mais retirado do solo pelas plantas. Este mineral atua do processo de regulação do potencial osmótico das células, é ativador de muitas enzimas envolvidas na respiração e fotossíntese, participa na translocação de carboidratos, aumenta a resistência à salinidade, geada, seca, doenças e ao acamamento (LAVRES JÚNIOR \& MONTEIRO, 2002). 
Neste trabalho foram avaliados os efeitos da fertilização potássica sobre a produção de forragem e composição química de Panicum maximum cv. Mombaça.

\section{Material e Métodos}

O ensaio foi conduzido em casa-de-vegetação, utilizando-se um Podzólico Vermelho-Amarelo, textura argilosa, o qual apresentava as seguintes características químicas: $\mathrm{pH}=5,7 ; \mathrm{Ca}+\mathrm{Mg}=2,9 \mathrm{cmol} / \mathrm{dm}^{3} ; \mathrm{P}=2 \mathrm{mg} / \mathrm{kg}$ e K $=42 \mathrm{mg} / \mathrm{kg}$. O solo foi coletado na camada arável $(0$ a $20 \mathrm{~cm})$, destorroado e passado em peneira com malha de $6 \mathrm{~mm}$ e posto para secar ao ar.

O delineamento experimental foi em blocos casualizados com três repetições. Os tratamentos consistiram de cinco doses de potássio $(0,15,30$, 45 e $60 \mathrm{mg} / \mathrm{kg}$ de solo), aplicadas sob a forma de cloreto de potássio, quando do plantio e uniformemente misturadas com o solo.

A adubação de estabelecimento constou da aplicação de $22 \mathrm{mg}$ de $\mathrm{P} / \mathrm{kg}$ de solo, sob a forma de superfosfato triplo. Cada unidade experimental constou de um vaso com capacidade para $3,0 \mathrm{dm}^{3}$ de solo seco. Dez dias após a emergência das plantas executou-se o desbaste, deixando-se duas plantas/vaso. O controle hídrico foi realizado diariamente através da pesagem dos vasos, mantendo-se o solo em $80 \%$ de sua capacidade de campo.

Durante o período experimental foram realizados três cortes a intervalos de 45 dias e a $15 \mathrm{~cm}$ acima do solo. Os parâmetros avaliados foram rendimento de matéria seca (MS), teores de proteína bruta (PB), fósforo, potássio, cálcio e magnésio. Foram ajustadas as equações de regressão para rendimento de MS (variável dependente) e teor de potássio (variável independente) (equação 1) e para teor de potássio como variável dependente dos níveis de potássio aplicados (equação 2). Através da equação 1 calculou-se a dose de potássio aplicada relativa a $90 \%$ do rendimento máximo de MS, sendo este valor substituído na equação 2 para determinação do nível crítico interno de potássio. 


\section{Resultados e Discussão}

A adubação potássica afetou significativamente $(P<0,05)$ os rendimentos de MS da gramínea, sendo o maior valor obtido com a aplicação de $60 \mathrm{~g} / \mathrm{dm}^{3}$ de $\mathrm{K}(6,02 \mathrm{~g} /$ vaso), seguindo-se os verificados com a aplicação de 45 (5,86 $\mathrm{g} /$ vaso) e $30 \mathrm{mg}$ de $\mathrm{K} / \mathrm{dm}^{3}$ (5,65 $\mathrm{g} /$ vaso), os quais não diferiram entre si $(P>0,05)$. No entanto, a aplicação de $15 \mathrm{mg}$ de $\mathrm{K} / \mathrm{dm}^{3} \mathrm{~K}$ já proporcionou um incremento de $67,7 \%$ no rendimento de $M S$, em relação ao tratamento testemunha (Tabela 1). ANDRADE et al. (2000) e SOUZA et al. (2007) também relataram efeito positivo desse nutriente na produção das plantas de capimelefante Cv. Napier (Pennisetum purpureum Schum.) e capim-Tanzânia (Panicum maximum), muito embora, autores como ANDRADE et al. (1996) tenham revelado que o potássio não influenciou a produção do capim Brachiaria ruziziensis.

Tabela 1. Rendimento de matéria seca (MS), eficiência de utilização do potássio (EUK) e teores de proteína bruta (PB) de Panicum maximum cv. Mombaça, sob efeito de adubação potássica (K).

\begin{tabular}{cccc}
\hline Doses de K (mg/dm $\left.{ }^{3}\right)$ & MS (g/vaso) & $\begin{array}{c}\text { EUK (g de MS/mg de } \\
\text { K) }\end{array}$ & PB (\%) \\
\hline 0 & $2,45 \mathrm{~d}$ & $0,166 \mathrm{c}$ & $12,45 \mathrm{a}$ \\
15 & $4,11 \mathrm{c}$ & $0,253 \mathrm{~b}$ & $11,02 \mathrm{~b}$ \\
30 & $5,65 \mathrm{~b}$ & $0,319 \mathrm{a}$ & $10,21 \mathrm{bc}$ \\
45 & $5,86 \mathrm{~b}$ & $0,321 \mathrm{a}$ & $9,33 \mathrm{~cd}$ \\
60 & $6,02 \mathrm{a}$ & $0,325 \mathrm{a}$ & $8,98 \mathrm{~d}$ \\
\hline
\end{tabular}

Nas colunas, médias seguidas de mesma letra não diferem entre si $(P>0,05)$ pelo teste Tukey.

Os rendimentos de forragem ajustaram-se ao modelo quadrático de regressão (Figura 1). A dose de máxima eficiência técnica foi estimada em $51,5 \mathrm{mg}$ de $\mathrm{K} / \mathrm{dm}^{3}$, a qual foi inferior às relatadas por GUTTERIDGE (1978) 
para Brachiaria mutica $\left(87 \mathrm{mg} / \mathrm{dm}^{3}\right.$ ) e COSTA (1996) para B. brizantha cv. Marandu $\left(57,6 \mathrm{mg} / \mathrm{dm}^{3}\right)$.

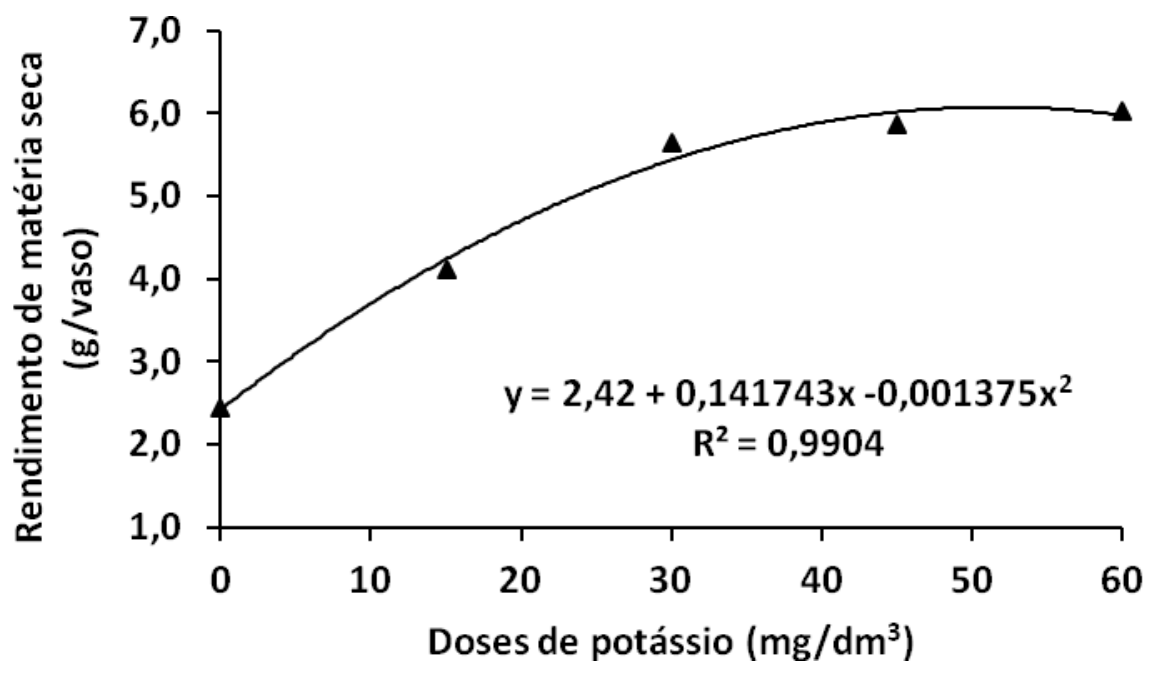

Figura 1. Rendimento de matéria seca (MS) de Panicum maximum cv. Mombaça, sob efeito de adubação potássica.

A eficiência de utilização de potássio foi afetada $(P<0,05)$ pelas doses aplicadas (Tabela 1, Figura 2). A análise de regressão indicou efeito quadrático, sendo o aproveitamento proporcional às doses aplicadas até a dose $47,5 \mathrm{mg} / \mathrm{dm}^{3}$. Estes resultados diferenciam dos encontrados em $P$. maximum cv. Tanzânia por SOUZA et al. (2004) que observaram redução da EUK com aumento da dose de potássio.

Os teores de PB e fósforo (Tabelas 1 e 2, Figura 3) decresceram, em função dos níveis de potássio aplicados, o que pode ser explicado pelo efeito de diluição com o aumento da produção de MS. A análise de regressão revelou linearidade negativa para os teores de PB $\left(\hat{y}=12,124-0,0575 x ; R^{2}=0,956\right)$ e fósforo $\left(\hat{y}=0,1838-0,0003 x ; R^{2}=0,968\right)$. TELES et al. (2011), trabalhando com níveis crescente de NPK em casa-de-vegetação, também verificaram decréscimos no teores de PB e fósforo de Brachiaria brizantha cv. MG-4 à medida que se ampliava as doses de potássio. Todavia, em Ribeirão Preto, ANDRADE et al. (1996), divulgaram que o potássio reduziu os teores de 
fósforo, sem influenciar os teores de PB de Brachiaria ruziziensis. Em Goiás, COSTA et al. (2006), trabalhando com Brachiaria brizantha cv. MG-5, num Argissolo Vermelho-Amarelo Eutrófico, observaram que os teores de PB passaram de 7,20\% para 10,57\%, quando se ampliaram as doses de zero para $200 \mathrm{~kg} \mathrm{ha}{ }^{-1}$ de $\mathrm{K}$. Considerando-se que teores de PB inferiores a 7\% são limitantes para que ocorra uma adequada fermentação ruminal (MINSON et al., 1984), neste experimento as respostas do capim-mombaça às doses de potássio aqui testadas atenderiam satisfatoriamente esta exigência.

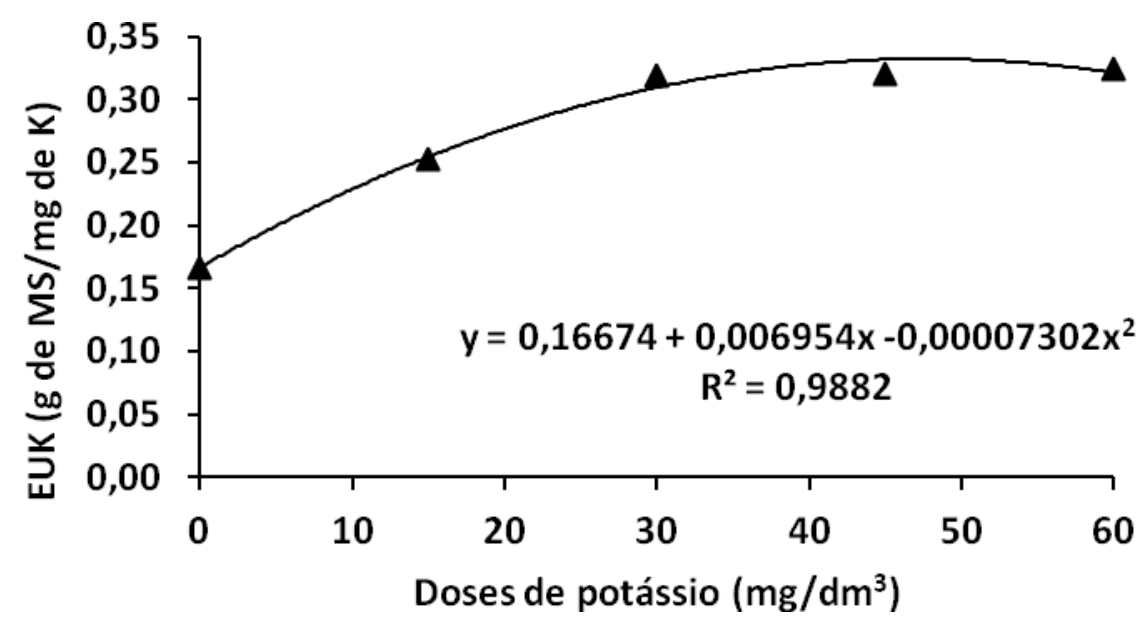

Figura 2. Eficiência de utilização do potássio (EUK) de Panicum maximum cv. Mombaça, sob efeito de adubação potássica. 
Tabela 2. Teores de fósforo, cálcio, magnésio e potássio de Panicum maximum cv. Mombaça, sob efeito de adubação potássica (K).

\begin{tabular}{ccccc}
\hline $\begin{array}{c}\text { Doses de K } \\
\left(\mathrm{mg} / \mathrm{dm}^{3}\right)\end{array}$ & Fósforo & Cálcio & Magnésio & Potássio \\
\cline { 2 - 5 } & & & $\%$ & \\
\hline 0 & $0,184 \mathrm{a}$ & $0,52 \mathrm{a}$ & $0,33 \mathrm{a}$ & $1,47 \mathrm{~d}$ \\
15 & $0,178 \mathrm{~b}$ & $0,48 \mathrm{a}$ & $0,38 \mathrm{a}$ & $1,62 \mathrm{c}$ \\
30 & $0,177 \mathrm{~b}$ & $0,50 \mathrm{a}$ & $0,32 \mathrm{a}$ & $1,77 \mathrm{~b}$ \\
45 & $1,170 \mathrm{c}$ & $0,47 \mathrm{a}$ & $0,30 \mathrm{a}$ & $1,82 \mathrm{a}$ \\
60 & $0,166 \mathrm{~d}$ & $0,45 \mathrm{a}$ & $0,36 \mathrm{a}$ & $1,85 \mathrm{a}$
\end{tabular}

Nas colunas, médias seguidas de mesma letra não diferem entre si $(P>0,05)$ pelo teste Tukey.

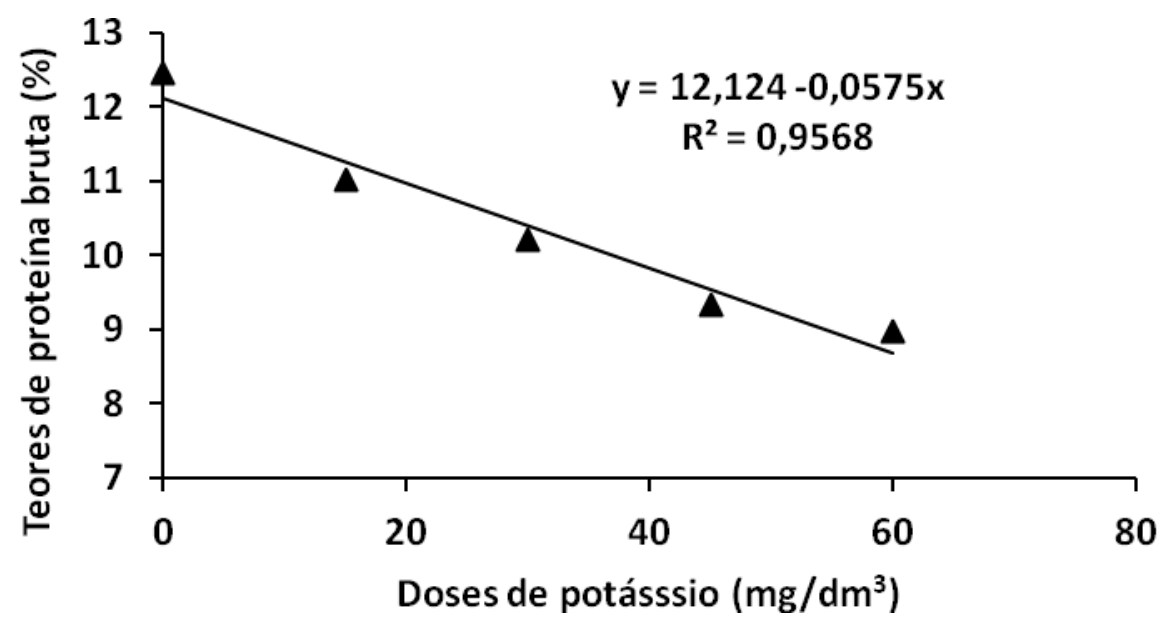

Figura 3. Teores de proteína bruta de Panicum maximum cv. Mombaça, sob efeito de adubação potássica.

Os teores de cálcio e magnésio não foram influenciados $(P>0,05)$ pela adubação potássica (Tabela 2). Contudo, considerando-se que não houve diluição com o aumento dos rendimentos de MS, observa-se um efeito positivo da adubação potássica na manutenção dos teores destes nutrientes. 
Os efeitos da adubação potássica sobre os teores de $\mathrm{K}$ foram descritos pelo modelo quadrático de regressão $\left(\hat{y}=1,476+0,1337 x-0,0012063 x^{2}\right.$; $\left.\mathrm{R}^{2}=0,98\right)$, sendo a dose de máxima eficiência técnica estimada em 55,4 mg de $\mathrm{K} / \mathrm{dm}^{3}$. Em geral, as concentrações de macronutrientes registradas para a gramínea são semelhantes às reportadas por COSTA et al. (2004a,b) para diversas cultivares de Panicum maximum.

O nível crítico interno de potássio, determinado através da equação que relacionou a dose de $\mathrm{K}$ necessária para a obtenção de $90 \%$ do rendimento máximo de MS, foi estimado em 1,75\%, o qual foi obtido com a aplicação de $42,27 \mathrm{mg}$ de $\mathrm{K} / \mathrm{dm}^{3}$. Este valor é superior aos relatados por TOLEDO (1986) para Hyparrhenia rufa $(1,15 \%)$, Andropogon gayanus $(0,95 \%)$, B. brizantha $(0,82 \%)$ e $B$. humidicola $(0,74 \%)$, contudo semelhante ao reportado por MONTEIRO (2005) para P. maximum cv. Mombaça (1,73\%).

\section{Conclusões}

Os rendimentos de MS e os teores de $\mathrm{K}$ foram incrementados pela adubação potássica, ocorrendo o inverso quanto aos teores de proteína bruta e fósforo, enquanto que os teores de cálcio e magnésio não foram afetados.

A dose de máxima eficiência técnica para o rendimento de MS foi estimada em $51,5 \mathrm{mg}$ de $\mathrm{K} / \mathrm{dm}^{3}$ e o nível crítico interno de $\mathrm{K}$ relacionado com $90 \%$ do rendimento máximo de MS em $1,75 \%$.

\section{Referências Bibliográficas}

ANDRADE, A.C.; FONSECA, D.M.; GOMIDE, J.A. et al. Produtividade e valor nutritivo do capimelefante cv. Napier sob doses crescentes de nitrogênio e potássio. Revista Brasileira de Zootecnia, v.29, n.6, p.1589-1595, 2000.

ANDRADE, J.B.; BENINTENDE, R.P.; FERRARI JÚNIOR, E. et al. Efeito das adubações nitrogenada e potássica na produção e composição de Brachiaria ruziziensis. Pesquisa Agropecuária Brasileira, v.31, n.9, p.617-620, 1996. 
COSTA, N. de L. Programa de pesquisa com pastagens em Rondônia. Porto Velho: Embrapa Rondônia, 1996. 24p. (Embrapa Rondônia. Documentos, 32).

COSTA, N. de L.; GONÇALVES, C.A.; TOWNSEND, C.R. et al. Rendimento, composição química e valor nutritivo da forragem. In: COSTA, $N$ de L. (Ed.). Formação, manejo e recuperação de pastagens em Rondônia. Porto Velho: Embrapa Rondônia, 2004b. p.116-136.

COSTA, N. de L.; PAULINO, V.T.; RODRIGUES, A.N.A. et al. Calagem e adubação de pastagens. In: COSTA, $\mathrm{N}$ de L. (Ed.). Formação, manejo e recuperação de pastagens em Rondônia. Porto Velho: Embrapa Rondônia, 2004a. p.81-115.

COSTA, N de L.; MAGALHÃES, J.A.; PEREIRA, R.G.A. et al. Considerações sobre o manejo de pastagens na Amazônia Ocidental. Revista do Conselho Federal de Medicina Veterinária, Brasília, v.13, n.40, p.37-56, 2007.

GODOY, L.J.G.; VILLAS BOAS, R.L.; BACKES, C. et al. Doses de nitrogênio e potássio na produção de grama esmeralda. Ciência e Agrotecnologia, v.31, n.5, p. 326-1332, 2007.

GUTTERIDGE, R.C. Potassium fertilizer studies on Brachiaria mutica/Centrosema pubescens pastures grown on acid soils derived from coral limestone, Malaita, Solomon Islands. Tropical Agriculture, v.58, n.1, p.359-367, 1978.

JANK, L.; SAVIDAN, Y.; SOUZA, M.T. et al. Avaliação do germoplasma de Panicum maximum introduzido da África. 1. Produção forrageira. Revista da Sociedade Brasileira de Zootecnia, v.23, p.433-440, 1994.

LAVRES JÚNIOR, J.; MONTEIRO, F.A. Combinações de doses de nitrogênio e potássio para a produção e nutrição do capim-Mombaça. Boletim de Indústria Animal, v.59, n.2, p.101$114,2002$.

MINSON, D.J. Effects of chemical and physical composition of herbaje eaten upon intake. In: HACKER, J.B. (Ed.) Nutritional limits to animal production from pasture. Farnham Royal: CAB. p.167-182, 1984.

MOCHEL FILHO, W.J.E. Fluxo de biomassa, produção de forragem e composição químico-bromatológica do capim-Mombaça sob adubação e irrigação. Fortaleza: UFC, 2009. 96f. Dissertação (Mestrado em Zootecnia) - Universidade Federal do Ceará.

MONTEIRO, F.A. Amostragem de solo e de planta para fins de análises químicas: métodos e interpretação de resultados. In: SIMPÓSIO SOBRE MANEJO DA PASTAGEM, 22., 2005, Piracicaba. Anais... FEALQ: Piracicaba, 2005, p.151-179.

MÜLLER, M.S.; FANCELLI, A.L.; NETO, D.D. et al. Produtividade do Panicum maximum cv. Mombaça irrigado, sob pastejo rotacionado. Scientia Agrícola, v.9, n.3, p.427-433, 2002.

REYNOSO, R.R.; GARAY, A.H.; SILVA, S.C. et al. Acumulación de forraje, crecimiento y características estructurales del pasto Mombaza (Panicum maximum Jacq.), cosechado a diferentes intervalo de corte. Técnica Pecuaria en México, v.47, n.2, p.203-213, 2009.

SANTOS, P.M. Estudo de algumas características agronômicas de Panicum maximum (Jacq.) cvs. Tanzânia e Mombaça para estabelecer seu manejo. 1997. 62f. Dissertação (Mestrado em Produção Animal e Pastagens) - Escola Superior de Agricultura Luiz de Queiroz, Piracicaba, 1997. 
SOUZA, M.R.F.; PINTO, J.C.; OLIVEIRA, I.P. et al. Produção de forragem do capim-Tanzânia sob intervalos de corte e doses de potássio. Ciência e Agrotecnologia, v. 31, n. 5, p. 1532$1536,2007$.

SOUZA, M.R.F.; PINTO, J.C.; OLIVEIRA, I.P. et al. Eficiência de utilização do nutriente potássio pela forragem do capim-Tanzânia sob diferentes doses de potássio. In: ZOOTEC, 2004, Brasília. Anais... Brasília: ABZ, 2004. 3p.

TELES, T.G.R.M.; CARNEIRO, M. do S. de; SOARES, I. et al. Produção e composição química da Brachiaria brizantha cv. MG-4 sob efeito de adubação com NPK. Acta Scientiarum. Animal Sciences, v.33, p.137-143, 2011.

TOLEDO, J.M. Pasturas en trópico húmedo: perspectiva global. In: SIMPÓSIO DO TRÓPICO ÚMIDO, I., Belém, 1984. Anais... Belém: EMBRAPA-CPATU, 1986. v.5. Pastagem e Produção Animal, p.19-35. 